\title{
BMJ Open Benefits of adding a physician-staffed ambulance to bystander-witnessed out- of-hospital cardiac arrest: a community-based, observational study in Niigata, Japan
}

Nobuhiro Sato (D) , ${ }^{1}$ Tasuku Matsuyama, ${ }^{2}$ Kohei Akazawa, ${ }^{3}$ Kyoko Nakazawa, ${ }^{3}$ Yasuo Hirose ${ }^{1}$

To cite: Sato N, Matsuyama T, Akazawa $\mathrm{K}$, et al. Benefits of adding a physician-staffed ambulance to bystanderwitnessed out-of-hospital cardiac arrest: a communitybased, observational study in Niigata, Japan. BMJ Open 2019;9:e032967. doi:10.1136/ bmjopen-2019-032967

- Prepublication history for this paper is available online. To view these files, please visit the journal online (http://dx.doi. org/10.1136/bmjopen-2019032967).

Received 15 July 2019

Revised 22 October 2019

Accepted 04 November 2019

Check for updates

(C) Author(s) (or their employer(s)) 2019. Re-use permitted under CC BY-NC. No commercial re-use. See rights and permissions. Published by BMJ.

${ }^{1}$ Department of Emergency and Critical Care Medicine, Niigata City General Hospital, Niigata, Japan

${ }^{2}$ Department of Emergency Medicine, Kyoto Prefectural University of Medicine, Kyoto, Japan

${ }^{3}$ Department of Medical Informatics and Statistics, Niigata University Graduate School of Medicine, Niigata, Japan

Correspondence to Dr Nobuhiro Sato;

s_nobuhiro@hosp.niigata. niigata.jp

\section{ABSTRACT}

Objective This study aimed to assess the benefits of adding a physician-staffed ambulance to bystanderwitnessed out-of-hospital cardiac arrest using a community-based registry.

Design Population-based, retrospective cohort study. Setting An urban city with approximately 800000 residents.

Participants Patients aged $\geq 18$ years with bystanderwitnessed out-of-hospital cardiac arrests of medical aetiology in Niigata City, Japan, between January 2012 and December 2016, according to the Utstein style. Primary and secondary outcome measures The primary outcome was 1-month survival with a favourable neurological outcome, defined as a cerebral performance category score of 1 or 2 . We used logistic regression analysis to assess the association between favourable neurological outcome and prehospital physician involvement.

Results During the study period, a total of 4172 cardiac arrests were registered; of these, 892 patients with outof-hospital cardiac arrest were eligible for this analysis, among whom 135 (15.1\%) had prehospital physician involvement and 757 (84.9\%) did not have prehospital physician involvement. The percentage of favourable neurological outcomes was $20.7 \%$ (28 of 135) in those with physician involvement and $10.4 \%$ (79 of 757 ) in those without physician involvement $(p=0.001)$. Using multivariable logistic regression, prehospital physician involvement had an OR for a favourable neurological outcome of 3.44 (95\% Cl 1.64 to 7.23$)$.

Conclusions Among adults with out-of-hospital cardiac arrest, adding a physician-staffed ambulance was associated with significantly greater favourable neurological outcomes than standard emergency medical services.

\section{INTRODUCTION}

Out-of-hospital cardiac arrest (OHCA) is a major public health issue in the industrialised world. $^{12}$ The rate of survival after an OHCA has continued to increase as improvements
Strengths and limitations of this study

- This study investigated the benefits of adding a physician-staffed ambulance to bystanderwitnessed out-of-hospital cardiac arrest using a population-based registry.

- This study assessed the impact of well-established physician-staffed ambulance services that collaborate with emergency medical service (EMS) personnel without variation in EMS provision among different regions in Japan.

- We focused on bystander-witnessed cardiac arrests, which is helpful since this group has the highest survival rate.

- We did not adjust for baseline characteristics such as pre-existing illness.

- We did not adjust for characteristics concerning inhospital or postresuscitation care.

are made in 'chain of survival' linkages, that is, the early activation of emergency medical services (EMS), early cardiopulmonary resuscitation (CPR), early defibrillation, rapid patient transport to the emergency department and postcardiac arrest care. ${ }^{2-4}$

Optimal EMS configurations and staffing for out-of-hospital CPR remain controversial. ${ }^{5}$ Whether prehospital physician-staffed advanced life support services should be provided is still a matter of debate. ${ }^{6-9}$ Physician-staffed ambulances are in use in many European countries, ${ }^{6} 71011$ while paramedics in the USA are permitted to provide highly advanced support partially because physician-staffed ambulances are considered an inefficient use of physician resources. ${ }^{12}$ One meta-analysis showed that EMS physicianguided CPR is associated with improved return of spontaneous circulation (ROSC) rates, hospital admission rates and hospital 
discharge rates compared with paramedic-guided CPR in patients with OHCA. ${ }^{5}$ In that meta-analysis, two studies that used data obtained between 2005 and 2010 in Japan comprised almost $90 \%$ of the total sample size; therefore, those two studies had undue weight within the overall results. ${ }^{13} 14$ Most EMS in Japan were limited to providing advanced life support during the period between 2005 and 2010 because since July 2004 specially trained emergency life-saving technicians (ELSTs) were permitted to insert tracheal tubes, and since April 2006 they have been permitted to administer intravenous epinephrine under online medical control direction. ${ }^{15}$ However, the rate of administration for intravenous epinephrine was low $(6.25 \%)$ in the non-physician group, as compared with administration of epinephrine in European countries. ${ }^{714}$ Moreover, variation in EMS provision among different regions and countries has made it difficult to isolate the effects of physician-staffed advanced life support compared with ELST-delivered advanced life support.

The purpose of this study was to compare the effectiveness of adding a physician-staffed ambulance with that of standard EMS in terms of the outcomes in adults, using a community-based registry.

\section{METHODS}

\section{Study design and participants}

This study comprised an analysis of the Utstein Registry of the Fire and Disaster Management Agency, a prospective, population-based registry system for OHCA in Niigata City between 2012 and 2016. This study included all patients $\geq 18$ years of age with a bystander-witnessed OHCA of medical origin. Based on the international Utstein style, medical origin includes cases in which the cause of the cardiac arrest is presumed to be cardiac, other medical cause (eg, anaphylaxis, asthma, gastrointestinal bleeding) and in which there is no obvious cause of the cardiac arrest. ${ }^{16}$ Diagnoses were made by the overseeing physician in collaboration with the EMS rescuers. We excluded OHCAs of non-medical origin, unwitnessed OHCAs, EMS-witnessed OHCAs, OHCAs witnessed in long-term care facilities and patients with OHCA who had undergone transfer between hospitals from our analysis.

\section{A physician-staffed ambulance service in Niigata}

Whether a physician-staffed ambulance service is implemented depends on the area in Japan because of a shortage of emergency physicians. In limited areas, physicianstaffed ambulances are available. Moreover, a helicopter medical service is available in 43 prefectures. ${ }^{17-19}$

Niigata City, located on the north-west coast of Japan, has a population of 800000 people. EMS in Niigata City are two-tiered only when it is indicated for the protocol of physician-staffed ambulance service, and the physicianstaffed ambulance service is available all day unless active on another emergency call; therefore, a physician-staffed ambulance service cannot be activated if it is being used to treat another patient, if it has been dispatched and is en route to another patient, or if the emergency call has not been recognised by a dispatch centre as a situation conforming to protocol. In addition, a physician who is in charge of physician vehicle works concurrently in emergency department or intensive care unit in our hospital because we have a few emergency physicians and intensivists. Therefore, a physician-staffed ambulance service cannot be activated if emergency department or intensive care unit is busy. Niigata City has 2 tertiary care hospitals, 25 ambulances and 1 physician-staffed ambulance. Two tertiary care hospitals are certificated as critical care medical centre (CCMC) in Japan. In order to be licensed as a CCMC, a hospital needs to have $\geq 20$ beds and an intensive care unit for critically ill patients, and it should be able to provide highly specialised procedures such as extracorporeal membrane oxygenation or percutaneous coronary intervention, and target temperature management 24 hours a day. ${ }^{20}$ The physician-staffed ambulance comprises one emergency physician with $>1$ year of experience in an emergency department and three crewmembers trained in rescue, stabilisation, transportation and advanced care in traumatic and medical emergencies. Further, two of the three crewmembers are qualified ELSTs who are permitted to use invasive alternative airways, such as a laryngeal mask airway and the Combitube, to treat patients with cardiac arrest. ${ }^{17}$ For those who have completed the Additional National Standard Training course, tracheal intubation is the treatment of choice in the management of patients with cardiac arrest. Authorised ELSTs are able to administer epinephrine. ELSTs are allowed to use advanced airways, intravenous line and epinephrine administration only under online medical control direction. Indications for activating the physician-staffed ambulance service are as follows: bystander-witnessed cardiac arrest, severe trauma, stroke, acute coronary syndrome, anaphylactic shock or a mass casualty incident. Once a dispatch centre receives an emergency call, dispatchers request both a physicianstaffed ambulance from an emergency medical centre in Niigata City General Hospital and an ambulance from the nearest emergency medical centre if the patient is suspected to have one of the above emergencies. In the case where an ambulance arrives first on scene, physicianstaffed ambulance is sometimes cancelled by the ambulance personnel when the ELSTs do not need physician on scene, for example, the ELSTs consider the low probability of favourable outcome. In contrast, a standard ambulance is staffed with three crewmembers, including at least one ELST. These crewmembers are trained in rescue, stabilisation, transportation and advanced care in traumatic and medical emergencies.

\section{Data collection}

Data on patient characteristics (sex and age), bystander characteristics (bystander CPR and bystander defibrillation with automated external defibrillator), cardiac arrest characteristics (first documented rhythm and aetiology of cardiac arrest) and prehospital care characteristics 
(intravenous catheter insertion, epinephrine administration, advanced airway management and prehospital physician involvement) were collected from a communitybased Utstein registry.

\section{Outcome measures}

The primary outcome was 1-month survival with a favourable neurological outcome. Neurological outcome was assessed by inpatient-attending physicians using the Glasgow-Pittsburgh cerebral performance category scores 1 month post-OHCA. A cerebral performance category score of 1 (good performance) or 2 (moderate disability) was considered a favourable neurological outcome, and a cerebral performance category score of 3 (severe disability), 4 (vegetative state) or 5 (death) was considered a poor neurological outcome. ${ }^{21}$ The secondary outcome was 1-month survival rate and ROSC prior to arrival at hospital.

\section{Statistical analysis}

Univariate analyses were performed with $\chi^{2}$ tests and Fisher's exact tests for dichotomous variables and MannWhitney U tests for continuous variables.

Multivariable analyses for bystander-witnessed OHCA were used to assess factors associated with 1-month survival with a favourable neurological outcome using logistic regression models, and ORs with 95\% CIs were calculated. Potential confounding factors based on biological plausibility and previous studies were included in the multivariable analysis. ${ }^{22}{ }^{23}$ These variables included age (18-74 years, $\geq 75$ years), sex (male, female), cause of cardiac arrest (cardiac, non-cardiac), first documented rhythm (shockable (ventricular fibrillation or ventricular tachycardia), non-shockable), public-access automated external defibrillator use (yes, no), bystander-initiated CPR (yes, no), dispatcher instruction (yes, no), response time, intravenous fluids and epinephrine administration (yes, no), and advanced airway management (yes, no). In the subgroup analyses, we stratified the model according to first documented rhythm, epinephrine administration and advanced airway management. Furthermore, we assessed interactions between a 1-month survival rate with a favourable neurological outcome and the presence of a physician according to first documented rhythm, epinephrine administration and advanced airway management using generalised linear models. We entered the time from call to epinephrine administration as variables into the stratified analysis according to epinephrine administration. The threshold for significance was $\mathrm{p}<0.05$. All statistical analyses were conducted using SPSS V.23.0.

\section{Patient and public involvement}

No patients or public were involved in this study design, conduct or analysis.

\section{RESULTS}

During the 5-year study period, resuscitation attempts were performed in 4172 cardiac arrests (figure 1). Of the 3146 patients with OHCAs of medical origin, 1350 were witnessed by bystanders, and of these 892 patients were eligible for our analyses.

\section{Patient characteristics}

Patients' characteristics according to prehospital physician involvement are listed in table 1. A total of 135 (15.1\%) patients with OHCA were attended to by a physician prior to hospital arrival, whereas $757(84.9 \%)$ patients were treated by EMS personnel only. When comparing patients who did and did not have prehospital physician involvement, the patients were younger, a greater number of victims had received dispatch CPR instructions, more patients had a shockable rhythm at first rhythm check, more patients received epinephrine administration, and transport time was longer in the physician involvement group. In total, $60.9 \%$ of patients received epinephrine administration and $>90 \%$ of patients received an advanced airway; however, only few endotracheal intubations were performed in both groups.

The association between physician involvement and outcome Overall, 20.7\% of patients with OHCA with physician involvement and $10.4 \%$ of patients with OHCA without physician involvement were alive after 1 month with a favourable neurological outcome $(\mathrm{OR}=2.25,95 \% \mathrm{CI} 1.39$ to 3.62; adjusted $\mathrm{OR}=3.44,95 \%$ CI 1.64 to 7.23 ) (tables 2 and 3). Similar positive associations were observed for the ROSC prehospital arrival and 1-month survival rate (tables 2 and 3 ).

In the subgroup analyses, physician involvement was positively associated with a favourable neurological

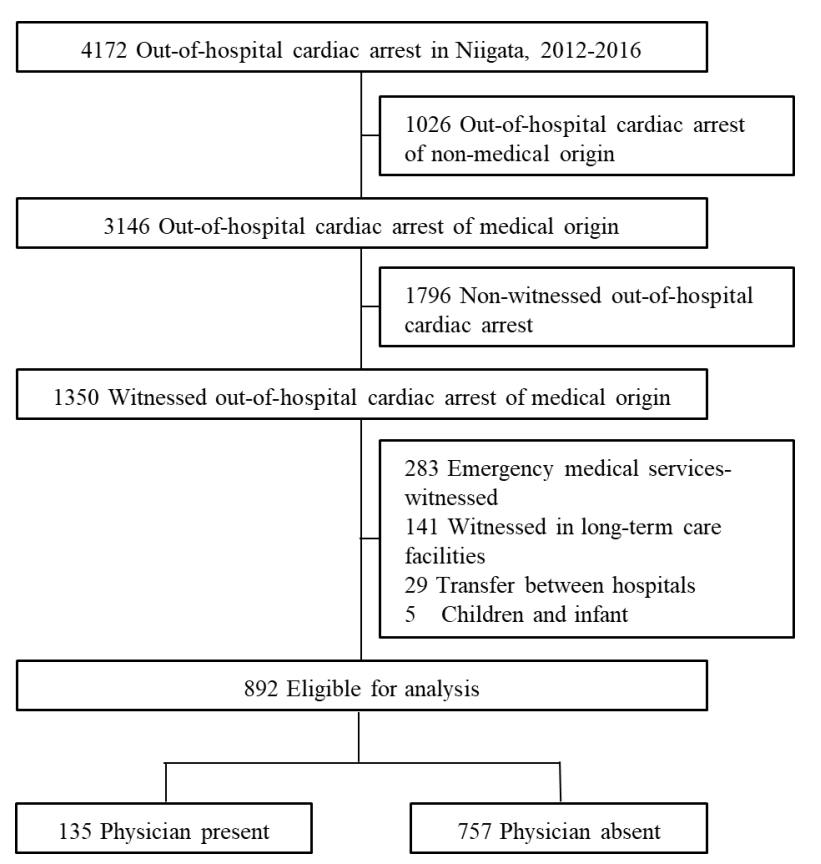

Figure 1 Patients with out-of-hospital cardiac arrests during the study period and patients included in the analysis. 
Table 1 Characteristics of patients with witnessed out-of-hospital cardiac arrests of medical origin according to prehospital physician involvement

\begin{tabular}{|c|c|c|c|c|c|c|c|}
\hline & \multicolumn{2}{|l|}{ All } & \multicolumn{2}{|c|}{ Physician present } & \multicolumn{2}{|c|}{ Physician absent } & \multirow[b]{2}{*}{ P value* } \\
\hline & $\mathrm{N}=892$ & $\%$ & $n=135$ & $\%$ & $\mathrm{n}=757$ & $\%$ & \\
\hline Age, median $(\mathrm{IQR})^{*} \dagger$ & \multicolumn{2}{|c|}{77 (64-85) } & \multicolumn{2}{|c|}{$66(57-78)$} & \multicolumn{2}{|c|}{$78(66-86)$} & $<0.001$ \\
\hline $18-74$ & 403 & 45.2 & 89 & 65.9 & 314 & 41.5 & \\
\hline$\geq 75$ & 489 & 54.8 & 46 & 34.1 & 443 & 58.5 & \\
\hline Female sex & 295 & 33.1 & 48 & 35.6 & 247 & 32.6 & 0.505 \\
\hline Dispatcher instructions & 446 & 50.0 & 96 & 71.1 & 350 & 46.2 & $<0.001$ \\
\hline \multicolumn{7}{|l|}{ Location } & \multirow[t]{2}{*}{0.494} \\
\hline Home & 658 & 73.8 & 100 & 74.1 & 558 & 73.7 & \\
\hline Work & 29 & 3.3 & 7 & 5.2 & 22 & 2.9 & \\
\hline Public area & 158 & 17.7 & 22 & 16.3 & 136 & 18.0 & \\
\hline Other & 47 & 5.3 & 6 & 4.4 & 41 & 5.4 & \\
\hline Bystander CPR & 453 & 50.8 & 81 & 60.0 & 372 & 49.1 & 0.020 \\
\hline Family & 245 & 27.5 & 46 & 34.1 & 199 & 26.3 & \\
\hline Acquaintance & 37 & 4.1 & 10 & 7.4 & 27 & 3.6 & \\
\hline Medical staff & 26 & 2.9 & 7 & 5.2 & 19 & 2.5 & \\
\hline Passers-by & 21 & 2.4 & 3 & 2.2 & 18 & 2.4 & \\
\hline Other & 124 & 13.9 & 15 & 11.1 & 109 & 14.4 & \\
\hline Bystander defibrillation with $\mathrm{AED}^{*} \neq$ & 25 & 2.8 & 3 & 2.2 & 22 & 2.9 & 0.462 \\
\hline Cardiac origin & 551 & 61.8 & 90 & 66.7 & 461 & 60.9 & 0.204 \\
\hline Shockable rhythm & 205 & 23.0 & 51 & 37.8 & 154 & 20.3 & $<0.001$ \\
\hline Response time, min, median (IQR) $\dagger$ & 9 (7- & & $8(7-$ & & $9(7-$ & & 0.021 \\
\hline $\begin{array}{l}\text { Time from call to defibrillation by } \\
\text { EMS, min, median (IQR) } \dagger\end{array}$ & $10(8-$ & & $10(8-$ & & $10(8-$ & & 0.687 \\
\hline Intravenous catheter insertion & 637 & 71.4 & 110 & 81.5 & 527 & 69.6 & 0.005 \\
\hline Epinephrine administration & 543 & 60.9 & 107 & 79.3 & 436 & 57.6 & $<0.001$ \\
\hline Advanced airway management & 837 & 93.8 & 128 & 94.8 & 709 & 93.7 & 0.607 \\
\hline Endotracheal intubation & 2 & 0.2 & 0 & 0.0 & 2 & 0.3 & \\
\hline $\begin{array}{l}\text { Time from call to epinephrine } \\
\text { administration, min, median (IQR) } \dagger\end{array}$ & $22(18$ & & $20(17$ & & $22(18$ & & 0.029 \\
\hline Scene time† & $23(18$ & & $24(19$ & & $23(18$ & & 0.237 \\
\hline$\leq 15 \min$ & 109 & 12.2 & 12 & 8.9 & 97 & 12.8 & \\
\hline$>15 \min$ to $<30 \mathrm{~min}$ & 629 & 70.5 & 97 & 71.9 & 532 & 70.3 & \\
\hline$\geq 30 \mathrm{~min}$ & 154 & 17.3 & 26 & 19.3 & 128 & 16.9 & \\
\hline Transport time $\dagger$ & $12(8-$ & & $15(9-$ & & $12(8-$ & & 0.007 \\
\hline Time from call to hospital $\dagger$ & $44(37$ & & $45(39$ & & $44(37$ & & 0.056 \\
\hline
\end{tabular}

${ }^{*}$ Comparisons between the 2 groups were evaluated using Mann-Whitney $U$ test for continuous variables and $\chi^{2}$ test or Fisher's exact test for categorical variables. The bold $\mathrm{P}$ values are statistically significant.

†Mann-Whitney U test.

‡Fisher's exact test.

AED, automated external defibrillator; CPR, cardiopulmonary resuscitation; EMS, emergency medical service.

outcome in terms of shockable rhythm, epinephrine administration and advanced airway management (table 4). In addition, 1-month survival rates with a favourable neurological outcome had a statistically significant association with epinephrine administration and with the presence of a physician.

\section{DISCUSSION}

In this community-based, observational study, we found that ROSC prior to hospital arrival, 1-month survival rates and favourable neurological outcomes were positively associated with adding a physician-staffed ambulance. 
Table 2 Unadjusted survival rate for ROSC prior to hospital arrival, 1-month survival rate and favourable neurological outcome rate

\begin{tabular}{|c|c|c|c|c|c|}
\hline & \multicolumn{3}{|l|}{ n (\%) } & \multirow[b]{2}{*}{$\begin{array}{l}\text { Unadjusted OR } \\
(95 \% \mathrm{Cl})\end{array}$} & \multirow[b]{2}{*}{ P value } \\
\hline & All $(\mathrm{N}=892)$ & $\begin{array}{l}\text { Presence of } \\
\text { physician }(n=135)\end{array}$ & $\begin{array}{l}\text { Absence of } \\
\text { physician }(n=757)\end{array}$ & & \\
\hline ROSC prior to hospital arrival & $214(24.0)$ & $60(44.4)$ & $154(20.3)$ & 3.13 (2.14 to 4.59$)$ & $<0.001$ \\
\hline 1-month survival & $143(16.0)$ & $37(27.4)$ & $106(14.0)$ & 2.32 (1.51 to 3.57 ) & $<0.001$ \\
\hline $\begin{array}{l}\text { Neurologically favourable } \\
\text { survival }\end{array}$ & $107(12.0)$ & $28(20.7)$ & 79 (10.4) & 2.25 (1.39 to 3.62$)$ & 0.001 \\
\hline
\end{tabular}

${ }^{*}$ Comparisons between the 2 groups were evaluated using $\chi^{2}$ test. The bold $\mathrm{P}$ values are statistically significant.

ROSC, return of spontaneous circulation.

One significant study finding was the improvement in neurological outcome with adding a physician-staffed ambulance. Several prior studies have reported associations between prehospital physician involvement and improved survival outcomes, ${ }^{5914}$ but these studies did not assess neurological outcomes for surviving patients. The underlying mechanism of our findings may be multifactorial. A previous report showed that the combination of bystander CPR and advanced cardiac life support provided by physicians was the best approach for improving neurological outcome. ${ }^{13}$ Another nationwide study performed in Japan also reported that physician-staffed ambulances were associated with improved favourable neurological outcomes. ${ }^{24}$ However, in a previous nationwide study, there were wide variations in physician-staffed ambulance services (eg, whether a physician-staffed ambulance was requested from EMS at the scene, and in the skill sets of the attending physicians in the ambulances), compared with our well-established physician-staffed ambulance services that collaborate with EMS personnel, which might have resulted in our better outcome rates. In addition, physicians are more likely to comply with treatment guidelines and to possess up-to-date knowledge than other ambulance personnel. ${ }^{725}$ Physicians are also reportedly more efficient in managing procedures such as ECG analysis and team management. ${ }^{726}$ The presence of physicians as a designated team leader, with experience and knowledge to provide oversight during resuscitation, may explain the increased focus on quality of care. ${ }^{14}$ On the other hand, another reason is that more personnel on scene might be associated with improved survival of OHCA or favourable neurological outcome rather than the presence of a physician. A prior observational study has shown that having five or more EMS personnel on scene was associated with higher rate of survival to hospital discharge. ${ }^{27}$ Another observational study in Japan also demonstrated

Table 3 Multivariable associations of prehospital predictors with outcomes

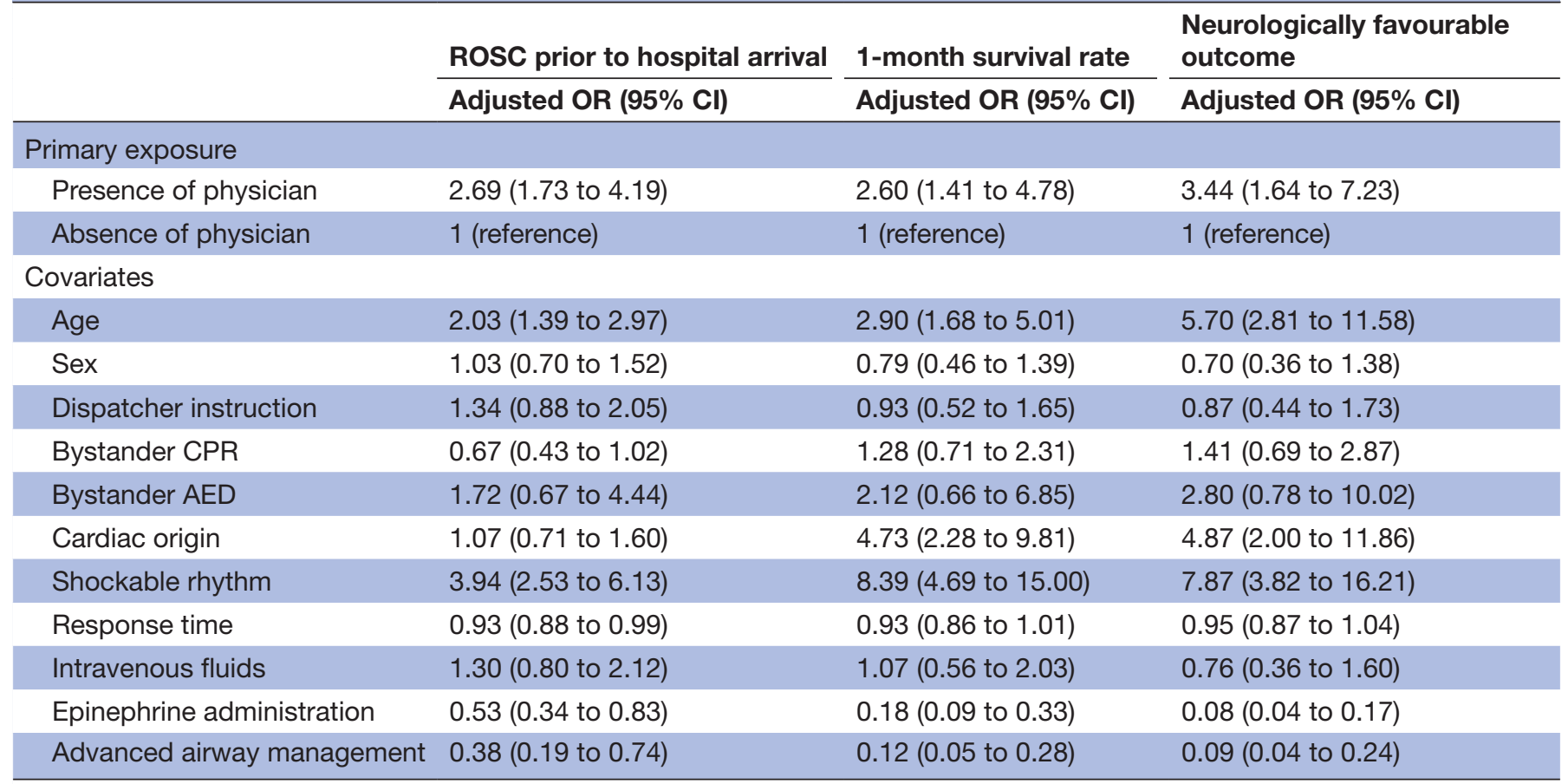

AED, automated external defibrillator; CPR, cardiopulmonary resuscitation; ROSC, return of spontaneous circulation. 
Table 4 Stratified analyses for outcomes according to first documented rhythm, epinephrine administration and advanced airway management

\section{Neurologically favourable outcome}

\begin{tabular}{|c|c|c|c|c|}
\hline \multirow{3}{*}{ Stratification } & & \multirow{3}{*}{ Adjusted OR (95\% Cl) } & \multirow{3}{*}{$\begin{array}{l}P \text { value for } \\
\text { interaction }\end{array}$} \\
\hline & & & & \\
\hline & & $\%$ & & \\
\hline First documented rhythm & & & & 0.159 \\
\hline \multicolumn{5}{|l|}{ Shockable } \\
\hline Physician present & $23 / 51$ & 45.1 & $4.09(1.57 \text { to } 10.64)^{\star}$ & \\
\hline Physician absent & $54 / 154$ & 35.1 & Reference & \\
\hline \multicolumn{5}{|l|}{ Non-shockable } \\
\hline Physician present & $5 / 84$ & 6.0 & $3.16(0.86 \text { to } 11.68)^{\star} \dagger$ & \\
\hline Physician absent & $25 / 603$ & 4.1 & Reference & \\
\hline Epinephrine administration & & & & 0.001 \\
\hline \multicolumn{5}{|l|}{ Yes } \\
\hline Physician present & $13 / 107$ & 12.1 & 3.29 (1.21 to 8.94$) \dagger \ddagger$ & \\
\hline Physician absent & $12 / 436$ & 2.8 & Reference & \\
\hline \multicolumn{5}{|l|}{ No } \\
\hline Physician present & $15 / 28$ & 53.6 & $2.77(0.73$ to 10.52$) \neq \S$ & \\
\hline Physician absent & $67 / 321$ & 20.9 & Reference & \\
\hline Advanced airway management & & & & 0.378 \\
\hline \multicolumn{5}{|l|}{ Yes } \\
\hline Physician present & $23 / 128$ & 18.0 & 3.25 (1.49 to 7.06$) \S \rrbracket$ & \\
\hline Physician absent & $55 / 709$ & 7.8 & Reference & \\
\hline \multicolumn{5}{|l|}{ No } \\
\hline Physician present & $5 / 7$ & 71.4 & Not analysed & \\
\hline Physician absent & $24 / 48$ & 50.0 & Reference & \\
\hline
\end{tabular}

*The bold $P$ values are statistically significant.

†Adjusted for age, sex, cause of cardiac arrest, public-access AED use, bystander-initiated CPR, dispatcher instruction, response time, intravenous fluids, epinephrine administration and advanced airway management.

$\ddagger$ Adjusted for age, sex, cause of cardiac arrest, first documented rhythm, public-access AED use, bystander-initiated CPR, dispatcher instruction, response time, intravenous fluids, advanced airway management and time from call to epinephrine.

§Adjusted for age, sex, cause of cardiac arrest, first documented rhythm, public-access AED use, bystander-initiated CPR, dispatcher instruction, response time, intravenous fluids and advanced airway management.

ПAdjusted for age, sex, cause of cardiac arrest, first documented rhythm, public-access AED use, bystander-initiated CPR, dispatcher instruction, response time, intravenous fluids and epinephrine administration.

AED, automated external defibrillator; CPR, cardiopulmonary resuscitation.

that on-scene three-ELST group was associated with improved favourable neurological outcome from OHCA compared with on-scene one-ELST group. ${ }^{28}$ Therefore, more personnel on scene might be more important than the presence of prehospital physician in the current system.

In the subgroup analyses, patients with prehospital physician involvement had neurological outcomes that were more favourable in all situations. However, a significant improvement in outcome was noted when epinephrine was administered. Previous studies have shown that a shorter time to epinephrine administration is associated with better patient outcomes after in-hospital cardiac arrest. ${ }^{29-31}$ Physicians may have more experience in establishing vascular access. In addition, physicians can use intraosseous access, while EMS personnel are not permitted to establish intraosseous access in Japan. Furthermore, ELSTs are allowed to administer epinephrine and intravenous fluid as well as intubate only after calling a physician, which might create an added delay for EMS drive care. Therefore, extending the procedures done by ELSTs might also be a solution as the paramedics in countries like the USA or Canada are allowed. In our study, there was a significant decrease in the time from the call to epinephrine administration in patients with prehospital physician involvement compared with patients without prehospital physician involvement. In contrast, there was no significant interaction in terms of performing advanced airway management. In Japan, ELSTs are permitted to use supraglottic airway devices. According to our study, more than $90 \%$ of patients received an advanced airway, and most of these involved 
supraglottic airway devices. Because ELSTs are familiar with supraglottic airway devices, ${ }^{17}$ superiority with advanced airway management by physicians may not have been shown.

The baseline characteristics of the patients who did and did not have prehospital physician involvement differed in our study. Unfortunately, we did not know the detailed reason why the physician-staffed ambulance was not dispatched on the 757 cases and the number in which the first arriving ambulance cancelled the physician ambulance. Therefore, selection bias might exist. We also consider that observational studies cannot avoid such selection bias, but we believe our findings provide important suggestions to perform a randomised controlled trial in the future which will reveal the actual impact of physician-staffed ambulance service. On the other hand, the cost and availability of physician ambulance vehicle would need to be considered if physicianstaffed ambulance services were proved to be effective. It is impractical to dispatch physicians to all witnessed OHCA patients when considering limited cost and resource; therefore, increasing EMS personnel on scene or extending the procedures done by ELSTs like in North America (eg, administer intravenous epinephrine without online medical control direction or establish intraosseous access) might be a solution.

\section{Limitations}

Our study has some limitations. First, our analyses could not adjust for characteristics concerning in-hospital or postresuscitation care. However, it appears likely that most patients with OHCA were transported to specific certificated hospitals that perform postresuscitation care in Niigata City. Second, this study could not adjust baseline characteristics such as pre-existing illness, which might affect the outcome of OHCA. Third, although this observational study adjusted for as many covariates as possible, we could not exclude possible residual confounding factors. Finally, some of the basic characteristics were different between patients with and without prehospital physician involvement. Selection bias as mentioned above might exist. However, we adjusted for such factors to the best of our ability and excluded OHCAs occurring in long-term care facilities where physician-staffed ambulances are frequently cancelled because of the low probability of a favourable outcome. Moreover, the physician-staffed ambulance service was essentially available 24/7 unless the physicians were attending to other patients, or if they had been dispatched and were en route to other patients, or the dispatch centre did not recognise a witnessed OHCA, or if emergency department or intensive care unit is busy because a physician who is in charge of a physician vehicle works concurrently in emergency department or intensive care unit in our hospital. Furthermore, a randomised controlled study would seem reasonable to adjust the baseline differences between groups and unmeasured confounder, removing some of the other differences such as the number of personnel on scene or ability to establish intraosseous access.

\section{CONCLUSIONS}

In conclusion, this community-based, observational study found that adding a physician-staffed ambulance was positively associated with 1-month survival and with favourable neurological outcomes. Further prospective research such as a randomised controlled trial will be warranted.

Acknowledgements The authors acknowledge Niigata City Fire Bureau for their assistance with this project.

Contributors NS conceived the study. TM, KA, KN and YH supervised the conduct of the trial and data collection. NS managed the data, including quality control. TM and KA provided statistical advice on the study design and analysed the data. NS chaired the data oversight committee. NS, TM and YH drafted the manuscript, and all authors contributed substantially to its revision. NS takes responsibility for the paper as a whole. All authors read and approved the final manuscript.

Funding The authors have not declared a specific grant for this research from any funding agency in the public, commercial or not-for-profit sectors.

Competing interests None declared.

Patient consent for publication Not required.

Ethics approval This study was approved by the Institutional Ethics Review Board of Niigata City General Hospital (17-060), and the requirement for patient informed consent was waived.

Provenance and peer review Not commissioned; externally peer reviewed.

Data availability statement Data are available upon reasonable request.

Open access This is an open access article distributed in accordance with the Creative Commons Attribution Non Commercial (CC BY-NC 4.0) license, which permits others to distribute, remix, adapt, build upon this work non-commercially, and license their derivative works on different terms, provided the original work is properly cited, appropriate credit is given, any changes made indicated, and the use is non-commercial. See: http://creativecommons.org/licenses/by-nc/4.0/.

ORCID iD

Nobuhiro Sato http://orcid.org/0000-0003-1624-7596

\section{REFERENCES}

1 Bhanji F, Donoghue AJ, Wolff MS, et al. Part 14: education: 2015 American heart association guidelines update for cardiopulmonary resuscitation and emergency cardiovascular care. Circulation 2015;132:S561-73.

2 Monsieurs KG, Nolan JP, Bossaert LL, et al. European resuscitation Council guidelines for resuscitation 2015: section 1. Executive summary. Resuscitation 2015;95:1-80.

3 Kronick SL, Kurz MC, Lin S, et al. Part 4: systems of care and continuous quality improvement: 2015 American heart association guidelines update for cardiopulmonary resuscitation and emergency cardiovascular care. Circulation 2015;132:S397-413.

4 Iwami T, Nichol G, Hiraide A, et al. Continuous improvements in 'chain of survival' increased survival after out-of-hospital cardiac arrests: a large-scale population-based study. Circulation 2009;119:728-34.

5 Böttiger BW, Bernhard M, Knapp J, et al. Influence of EMSphysician presence on survival after out-of-hospital cardiopulmonary resuscitation: systematic review and meta-analysis. Crit Care 2016;20:4.

6 Estner HL, Günzel C, Ndrepepa G, et al. Outcome after out-ofhospital cardiac arrest in a physician-staffed emergency medical system according to the Utstein style. Am Heart J 2007;153:792-9.

7 Olasveengen TM, Lund-Kordahl I, Steen PA, et al. Out-of hospital advanced life support with or without a physician: effects on quality of CPR and outcome. Resuscitation 2009;80:1248-52.

8 Böttiger BW, Grabner C, Bauer H, et al. Long term outcome after out-of-hospital cardiac arrest with physician staffed emergency 
medical services: the Utstein style applied to a midsized urban/ suburban area. Heart 1999:82:674-9.

9 Hamilton A, Steinmetz J, Wissenberg M, et al. Association between prehospital physician involvement and survival after out-ofhospital cardiac arrest: a Danish nationwide observational study. Resuscitation 2016;108:95-101

10 Krüger AJ, Skogvoll E, Castrén M, et al. Scandinavian pre-hospital physician-manned Emergency Medical Services-same concept across borders? Resuscitation 2010;81:427-33.

11 Empana J-P, Sauval P, Ducimetiere P, et al. Increase in out-ofhospital cardiac arrest attended by the medical mobile intensive care units, but not myocardial infarction, during the 2003 heat wave in Paris, France. Crit Care Med 2009;37:3079-84.

12 Cummins RO, Ornato JP, Thies WH, et al. Improving survival from sudden cardiac arrest: the 'chain of survival' concept. A statement for health professionals from the Advanced Cardiac Life Support Subcommittee and the Emergency Cardiac Care Committee, American Heart Association. Circulation 1991;83:1832-47.

13 Yasunaga $\mathrm{H}$, Horiguchi $\mathrm{H}$, Tanabe $\mathrm{S}$, et al. Collaborative effects of bystander-initiated cardiopulmonary resuscitation and prehospital advanced cardiac life support by physicians on survival of out-ofhospital cardiac arrest: a nationwide population-based observational study. Crit Care 2010;14.

14 Hagihara A, Hasegawa M, Abe T, et al. Physician presence in an ambulance CAR is associated with increased survival in out-ofhospital cardiac arrest: a prospective cohort analysis. PLoS One 2014;9:e84424

15 Kitamura T, Iwami T, Kawamura T, et al. Nationwide public-access defibrillation in Japan. N Engl J Med 2010;362:994-1004.

16 Perkins GD, Jacobs IG, Nadkarni VM, et al. Cardiac arrest and cardiopulmonary resuscitation outcome reports: update of the Utstein resuscitation registry templates for out-of-hospital cardiac arrest: a statement for healthcare professionals from a task force of the International liaison Committee on resuscitation (American heart association, European resuscitation Council, Australian and New Zealand Council on resuscitation, heart and stroke Foundation of Canada, InterAmerican heart Foundation, resuscitation Council of southern Africa, resuscitation Council of Asia); and the American heart association emergency cardiovascular care Committee and the Council on cardiopulmonary, critical care, perioperative and resuscitation. Circulation 2015;132:1286-300.

17 Tanigawa K, Tanaka K. Emergency medical service systems in Japan: past, present, and future. Resuscitation 2006;69:365-70.

18 Emergency Medical Network of Helicopter and Hospital. Where are they deployed? Tokyo. Available: http://www.hemnet.jp/english/ where/index.html [Accessed 8 Jul 2019].

19 Tsuchiya A, Tsutsumi Y, Yasunaga H. Outcomes after helicopter versus ground emergency medical services for major trauma--propensity score and instrumental variable analyses: a retrospective nationwide cohort study. Scand J Trauma Resusc Emerg Med 2016;24:140.
20 Matsuyama T, Kiyohara K, Kitamura T, et al. Hospital characteristics and favourable neurological outcome among patients with out-of-hospital cardiac arrest in Osaka, Japan. Resuscitation 2017;110:146-53.

21 Jacobs I, Nadkarni V, Bahr J, et al. Cardiac arrest and cardiopulmonary resuscitation outcome reports: update and simplification of the Utstein templates for resuscitation registries: a statement for healthcare professionals from a task force of the International liaison Committee on resuscitation (American heart association, European resuscitation Council, Australian resuscitation Council, New Zealand resuscitation Council, heart and stroke Foundation of Canada, InterAmerican heart Foundation, resuscitation councils of southern Africa). Circulation 2004;110:3385-97.

22 Kitamura T, Kiyohara K, Sakai T, et al. Public-access defibrillation and out-of-hospital cardiac arrest in Japan. N Engl J Med 2016;375:1649-59.

23 Mikkelsen S, Lossius HM, Toft P, et al. Characteristics and prognoses of patients treated by an anaesthesiologist-manned prehospital emergency care unit. A retrospective cohort study. BMJ Open 2017;7:e014383.

24 Goto Y, Funada A, Goto Y. Impact of prehospital physician-led cardiopulmonary resuscitation on neurologically intact survival after out-of-hospital cardiac arrest: a nationwide population-based observational study. Resuscitation 2019;136:38-46.

25 Kirves H, Skrifvars MB, Vähäkuopus M, et al. Adherence to resuscitation guidelines during prehospital care of cardiac arrest patients. Eur J Emerg Med 2007;14:75-81.

26 Schneider T, Mauer D, Diehl P, et al. Quality of on-site performance in prehospital advanced cardiac life support (ACLS). Resuscitation 1994;27:207-13.

27 Warren SA, Prince DK, Huszti E, et al. Volume versus outcome: more emergency medical services personnel on-scene and increased survival after out-of-hospital cardiac arrest. Resuscitation 2015;94:40-8.

28 Kajino K, Kitamura T, Iwami T, et al. Impact of the number of onscene emergency life-saving technicians and outcomes from out-ofhospital cardiac arrest in Osaka City. Resuscitation 2014;85:59-64.

29 Donnino MW, Salciccioli JD, Howell MD, et al. Time to administration of epinephrine and outcome after in-hospital cardiac arrest with nonshockable rhythms: retrospective analysis of large in-hospital data registry. BMJ 2014;348:g3028.

30 Ewy GA, Bobrow BJ, Chikani V, et al. The time dependent association of adrenaline administration and survival from out-ofhospital cardiac arrest. Resuscitation 2015;96:180-5.

31 Hansen M, Schmicker RH, Newgard CD, et al. Time to epinephrine administration and survival from Nonshockable out-ofhospital cardiac arrest among children and adults. Circulation 2018;137:2032-40. 